\title{
Editorial
}

\section{International Health Care Topics: Malaria Prevention Analyses, Nursing Perspective, and Patient Perspectives}

\author{
Akiko Kamimura*, Samin Panahi, Shannon Weaver \\ University of Utah, Salt Lake City, Utah, USA
}

The issue for May 2018 issue covered three main areas including two articles about Malaria treatment in Nigeria, two articles about healthcare workers, one from Saudi Arabia the other from Australia, and one article about patients satisfaction from the United States (US). There were 216 million Malaria cases in worldwide in 2016 [1]. The majority of Malaria cases and deaths occur in Africa [2]. Malaria is a main public issue in Nigeria [3]. The number of Malaria cases and deaths in Nigeria is greater than that in the rest of the world [4]. Articles entitled "Replacement Campaign of Long Lasting Insecticide Treated Nets in Ondo State, Southwest Nigeria, Heartland of Africa's Most Efficient Vector Species" and "Performance of Microscopy Method and Rapid Diagnostic Tests in Malaria Diagnosis amongst Pregnant Women in Lagos, Southwest Nigeria" contribute to improving prevention and treatment efforts for Malaria in Nigeria.

Supporting health care workers is very important to ensure quality of care. A number of previous studies examined the issue of burnout among nursing staff [5-7]. However, little is known about burnouts among nurses in Saudi Arabia. The article entitled "The Prevalence of Burnout Syndrome among Nursing Staff working at King Abdulaziz University Hospital, Jeddah, Saudi Arabia, 2017" will add the knowledge about the topic. In Australia, there is a shortage of aged care workers [8]. One of the reasons contributing to the shortage is unsupportive work environments [8]. The article entitled "Supporting Aged Care Workers to Understand and Respond to the Needs of Trans and Gender Diverse People: An Australian Co-designed Quality Improvement Initiative" presents strategies to support aged care workers in Australia, which would be beneficial for other developed countries in creating a more diverse the gender workforce to care for individuals across spectrum.

Finally, understanding patient perspectives is very important to improve quality of care and successfully manage health care organizations [9]. In particular, underserved populations may have very different perspectives about health care $[10,11]$. Free clinics which provide free or reduced fee health care services to under- or un- insured individuals have been taking an important role to serve the populations in the US [12]. While free clinic patients tend to be satisfied with medical care, few qualitative studies have examined satisfaction among free clinic patients $[13,14]$. The article entitled "Perspectives of Health Care
Services among Free Clinic Patients in the USA: A Qualitative Study" gathered the information about patient perspectives using an anonymous open-ended question which has not been used in any other US free clinic studies. This study will help enrich the knowledge about free clinic patients' perspectives using that particular data collection method and improve quality of health care for underserved populations.

\section{REFERENCES}

1. http://www.who.int/malaria/en/

2. http://www.who.int/en/news-room/fact-sheets/detail/ malaria

3. https://photos.state.gov/libraries/nigeria/231771/Public/ December-MalariaFactSheet2.pdf

4. https://www.cdc.gov/globalhealth/countries/nigeria/what/ malaria.htm

5. Abellanoza A, Provenzano-Hass N, Gatchel RJ (2018) Burnout in ER nurses: Review of the literature and interview themes. J Appl Biobehav Res. 23: 16.

6. Nogueira LD, de Sousa RMC, Guedes ED (2018) Burnout and nursing work environment in public health institutions. Rev Bras Enferm. 71: 336-342.

7. Pradas-Hernandez L, Ariza T, Gomez-Urquiza JL (2018) Prevalence of burnout in paediatric nurses: A systematic review and meta-analysis. PloS One. 13: 14.

8. https://www.emeraldinsight.com/doi/abs/10.1108/EDI-052017-0105

9. Fox S (2017) Patient experience: Why it is important to providers. Front Health Serv Manage. 33: 42-48.

10. https://www.cdc.gov/pcd/issues/2016/pdf/16_0236.pdf

11. Hooker RS (2013) Working with the medically underserved. CFP. 59: 339-340.

12. Brennan VM (ed.) (2013) Free Clinics: Local Responses to Health Care Needs. Baltimore, MD: Johns Hopkins University Press.

13. Kamimura A, Ashby J, Myers K (2015) Satisfaction with healthcare services among free clinic patients. J Community Health. 40: 62-72. 
14. Kamimura A, Chen J, Aguilera G (2017) Patient satisfaction and perspectives of continuity of care: A among free clinic patients in the USA qualitative study. Divers Equal Health Care. 14: 169-174.
ADDRESS OF CORRESPONDENCE: Akiko Kamimura, PhD, MSW, MA. Department of Sociology, University of Utah, 380 S 1530 E, Salt Lake City, Utah 84112, USA, Tel: +1-801585-5496; Fax: +1-801-585-3784; E-mail akiko.kamimura@ utah.edu

Submitted: May 24, 2018; Accepted: May 25, 2018; Published: June 01, 2018 